\title{
PARTIAL SEIZURES IN CHILDREN
}

\author{
Jain N, Mangal V
}

\section{ABSTRACT}

Seizure disorders are the most prevalent serious neurological disease. Partial seizures are the most common form of seizures in children. This prospective study was carried out to determine the etiology and intracranial lesions in children with partial seizures. During the period of 3 years, 172 children with partial seizures (>2 attacks) were included in the study. All children had contrast CT scan of head. About $70 \%$ of children had their first episode of seizure before 6 years of age. The most common type of seizures was complex partial and the most common lesion on CT scan head was ring enhancing lesion $(56.07 \%)$. For diagnosis of partial seizures detail history and CT Scan of Head are essential.

\section{Key Words: Partial seizures, neurocyticercosis, Tuberculoma, CT scan.}

\section{INTRODUCTION}

Epilepsy is defined as a randomly recurring symptom complex resulting from an episodic disturbance of CNS function, associated with an excessive, self limited, neuronal discharge. Variation in clinical manifestations result from variation in the portion of the brain involved. The incidence of epilepsy has been reported to range from $0.8 \%-1.1 \%^{1}$ and approximately $50 \%$ of all cases of epilepsy start in childhood. As per international league against epilepsy (ILAE 1989) all epilepsy cases are classified into two categories e.g. partial seizures and generalized seizures. ${ }^{2}$

\section{OBJECTIVE}

The aetiological factors of epilepsy differ markedly in children as compared to adults. This study was carried out for determining the underlying etiology on CT scan Head.

\section{MATERIAL AND METHOD}

The study was conducted prospectively over a three year period between Jan 2000-Dec. 2002 in the department of pediatrics, Nepalgunj Medical College, Nepalgunj, Nepal. 172 children with partial seizures defined as per I LAE. All these children had two or more than two attacks of unprovoked partial seizures. Children with neonatal convulsions, febrile convulsions and acute CNS infections were excluded. All the children were subjected to CT Scan of Head.

\section{RESULT}

Of the 172 children with partial seizures, $112(65.11 \%)$ were male and 60 (34.88\%) were females. The age of patients ranged between 6 months and 12 years. $69.8 \%$ of children (120/172) had their first episode of seizure before the age of six years. The seizures type were as follows:
(a) Simple Partial
$38(22.09 \%)$
(b) Complex Partial
$95(55.23 \%)$
(c) Partial Seizures with Secondary
generalization
$39(22.67 \%)$

The aetiological profile on CT Scan Head of partial seizures in these children is shown in table I.

* Nepalgunj Medical College, B.P. Chowk, Nepalgunj, Nepal.

Address for correspondence : Dr. Neeraj Jain

27 Mangal Nagar Saharanpur, India - 247001

Email: ishu12002@yahoo.com 


\begin{tabular}{|c|c|c|}
\hline Lesions & Number & $\%$ \\
\hline Normal & 65 & $37.79 \%$ \\
\hline Symptomatic & 107 & $62.20 \%$ \\
\hline ? Ring enhancing & & \\
\hline 1. Single & 54 & $50.46 \%$ \\
\hline 2. Multiple & 06 & $5.60 \%$ \\
\hline ? Cortical infract & 12 & $11.21 \%$ \\
\hline ? Cerebral atrophy & 10 & $9.34 \%$ \\
\hline ? $\quad$ Dilated Ventricles & 06 & $5.60 \%$ \\
\hline ? $\quad$ Encephalomalacia & 06 & $5.60 \%$ \\
\hline ? $\quad$ Calcifications & 04 & $3.73 \%$ \\
\hline$? \quad$ Brain tumor & 02 & $1.86 \%$ \\
\hline ? $\quad$ Gliosis & 03 & $2.80 \%$ \\
\hline ? $\quad$ Porencepnalic cyst & 02 & $1.86 \%$ \\
\hline ? $\quad$ Subdural effusion & 02 & $1.86 \%$ \\
\hline
\end{tabular}

Intracranial lesions were detected in 107 out of 172 children and the most commonly observed lesions on CT Scan of head were ring enhancing lesions which were multiple in 06 children and single in 54 children. Of these 60 patients 22 were diagnosed as tuberculoma using radiological criteria and supportive evidence of tuberculosis elsewhere and remaining 35 were treated as neurocyticercosis. Immunological tests for NCC and follow up CT scan were not done due to economic constraints.

\section{DISCUSSION}

Partial seizures in children represent a large percentage of epilepsy requiring an accurate diagnosis for appropriate management. A study of a cohort of 440 children observed partial seizures constitute a large percent $(41.7 \%)$ of seizure types in children. ${ }^{3}$ In developing countries like Nepal partial epilepsy is reported to be more frequent in all age groups. ${ }^{4}$

Analysis from clinical data and investigations revealed that ring enhancing lesions as neurocyticercosis were the commonest lesion. This has also been observed by other studies ${ }^{5}$ CT studies of partial seizures in children are very helpful in detecting small intracranial lesions and are reported to have a higher yield than those observed with generalized epilepsy. ${ }^{6}$ Abnormal scans have identified in $60-70 \%$ children with partial seizures. ${ }^{7}$ The findings of the present study are similar to other studies so far as the basic patterns of intracranial structural lesions are concerned. ${ }^{8,10}$

Thus partial seizures is the most common neurological disease of childhood, which causes great impact on the social as well as economic aspect of the under developed countries. Numerous relatively benign, episodic spells often are misdiagnosed and even treated as seizures. Therefore correct diagnosis and appropriate treatment should be more important.

\section{ACKNOWLEDGEMENTS}

We would like to thank Dr. S.K. Kanodia, Prof. S.K. Jha for their suggestions and Dr. Rinki Kalra, Mr. Krishna Panthi, Mr. Raees Sahi and Mrs. Pratibha Chaudhari for computing this manuscript.

\section{REFERENCES}

1. Agranal A., Aneja A., Taluka V. et. Al: Etiology of Partial Epilepsy. Indian pediatr. 1998; 35:49-52

2. Commission on classification and Teminology of intemational league Against Epilepsy, Proposal for revised classification of Epilepsies and Epileptic syndromes. Epilepsia. 1989; 30:38999

3. Kramer U., nevoy. Neufeld MV. et al: Epidemiology of Epilepsy in childhood, a cohort of 440 patients. Pediatr. Neurology. 1998; 18 (1) : 46-50

4. Senanayaka N. Romer GC; Epidemiology of Epilepsy in developing countries, Bull. WHO. 1993; 71:247-58

5. Kapoor M., Talukder B, Chowdhary V. et al: Intra Cranial structural lesions in young Epileptics, a computed tomography study; Indian Pediatr 1998; 35:537-41

6. Misra S, Verma R, Lekhra OP.et al; CT observations in Partial Seizures. Neurology India. 1994; 42:24-27

7. Kalra V: Management of childhood epilepsy. Indian J Pediatr. 2000 (SS) : S12-S21

8. Kumar R, Kumar A. Kohli $\mathrm{N}$ et al: Ring or disc like enhancing lesions in Partial Epilepsy in India. J Trop Pediatr: 1990; 36:13134

9. Garg RK, Karak B. Sharma AM et al: Single CT (ring) lesions in Epilepsy. Indian J Pediatr. 1999; 66:155-57

10. Wadia RS, Makhale aN. Kelkar AV, et al: Focal Epilepsy in India with special reference to lesions showing ring or disc like enhancement on contrast CT. J. Neurol . 1987;50:1298-1301. 